\title{
Article
}

\section{The Spatio-Temporal Analysis of Urban-Rural Coordinated Development and Its Driving Forces in Yangtze River Delta}

\author{
Daizhong Tang, Mengyuan Mao, Jiangang Shi and Wenwen Hua *
}

check for updates

Citation: Tang, D.; Mao, M.; Shi, J.; Hua, W. The Spatio-Temporal Analysis of Urban-Rural Coordinated Development and Its Driving Forces in Yangtze River Delta. Land 2021, 10, 495. https://doi.org/10.3390/ land10050495

Academic Editor: Nicholas Magliocca

Received: 10 April 2021

Accepted: 4 May 2021

Published: 7 May 2021

Publisher's Note: MDPI stays neutral with regard to jurisdictional claims in published maps and institutional affiliations.

Copyright: (c) 2021 by the authors. Licensee MDPI, Basel, Switzerland. This article is an open access article distributed under the terms and conditions of the Creative Commons Attribution (CC BY) license (https:// creativecommons.org/licenses/by/ $4.0 /)$.
School of Economics and Management, Tongji University, Shanghai 200092, China; tdzhong@tongji.edu.cn (D.T.); maomengyuan@tongji.edu.cn (M.M.); 84067@tongji.edu.cn (J.S.)

* Correspondence: 2030380@tongji.edu.cn

Abstract: This paper conducts an analytical study on the urban-rural coordinated development (URCD) in the Yangtze River Delta urban agglomeration (YRDUA), and uses data from 2000-2015 of 27 central cities to study the spatial and temporal evolution patterns of URCD and to discover the influencing factors and driving forces behind it through PCA, ESDA and spatial regression models. It reveals that URCD of the YRDUA shows an obvious club convergence phenomenon during the research duration. The regions with high-level URCD gather mainly in the central part of the urban agglomeration, while the remaining regions mostly have low-level URCD, reflecting the regional aggregation phenomenon of spatial divergence. At the same time, we split URCD into efficiency and equity: urban-rural efficient development (URED) also exhibits similar spatiotemporal evolution patterns, but the patterns of urban-rural balanced development (URBD) show some variability. Finally, by analyzing the driving forces in major years during 2000-2015, it can be concluded that: (i) In recent years, influencing factors such as government financial input and consumption no longer play the main driving role. (ii) Influencing factors such as industrialization degree, fixed asset investment and foreign investment even limit URCD in some years. The above results also show that the government should redesign at the system level to give full play to the contributing factors depending on the actual state of development in different regions and promote the coordinated development of urban and rural areas. The results of this study show that the idea of measuring URCD from two dimensions of efficiency and equity is practical and feasible, and the spatial econometric model can reveal the spatial distribution heterogeneity and time evolution characteristics of regional development, which can provide useful insights for urban-rural integration development of other countries and regions.

Keywords: urban-rural coordinated development; spatio-temporal evolution analysis; driving forces; the Yangtze River Delta urban agglomeration

\section{Introduction}

By referring to and summarizing the existing development experiences, we can find that the evolution of urban-rural relations has certain commonalities, and specific stage characteristics will be formed over time. The advancement of industrialization has led to the massive absorption of rural labor by cities, and the gap between town and country has gradually come to the fore, and a dichotomy has gradually emerged. [1,2]. Subsequently, the rise in productivity levels allowed cities to spread the effects of industrialization further into the countryside and drive rural development, gradually forming various development models such as "core-edge" [3] and "growth pole" [4]. With the further increase of urbanization, the linkage between cities and rural areas has become stronger, and the concept of urban agglomeration has been gradually formed. Different models of urban-rural agglomeration, such as the regional network model and the Desakota model, have been developed among different countries and regions [5]. At the same time, many scholars believe that with the continuous development and evolution of urban agglomerations, a relatively healthy and balanced relationship will be formed between 
cities and villages [6]. Through the integrated planning within urban agglomerations, the spatial pattern of urbanization will be continuously optimized, and the flow of factors within the whole region will contribute to the steady development and play a vital role as traction and a driving force in a larger regional context [7].

China's urban-rural development has also undergone the same phased process of moving from "confrontation" to "integration" since the founding of the country. Due to the planned economic system, the household registration system and some other control measures, the free flow of population, capital and other factors of production between town and country were not possible, and the urban-rural relationship centered on and dominated by cities made the gap expand rapidly, and the urban-rural dichotomy became an obstacle to modernization [8]. After the reform and opening up in 1978, China's urbanization accelerated in the context of the market economy system, and the connection between city and village began to emerge and develop. As a large amount of rural laborers have entered the cities to engage in non-farm industries [9], the government has begun to focus on the development of rural areas, encouraging rural areas to set up township enterprises and develop non-farm industries $[10,11]$. Scholars generally agree that both urban and rural areas experience remarkable development in social, economic and environmental aspects during this period. In particular, rural areas have experienced considerable growth in their lifestyle [12], employment [13], industrial development [14], land use [15], infrastructure conditions [16] and health care services [17], and produce dramatic changes. At the same time, many scholars have suggested that there are gaps in the development process between city and countryside in terms of the provision of public goods [18], urban and rural incomes [19], infrastructure allocation [20], investment in educational resources [21], rational land resource use [22] and other aspects. In the course of urban-rural development, China has gradually formed many urban agglomerations, including the Yangtze River Delta urban agglomeration (YRDUA), Beijing-Tianjin-Hebei urban agglomeration, GuangdongHong Kong-Macao Greater Bay Area, etc. All these urban agglomerations have a mega-city as their core and at least three or more large cities as their constituent units, forming a basic pattern of compact spatial organization and close economic ties based on developed transportation and communication infrastructure networks.

In addition to the above commonalities, China's development also exhibits some unique characteristics due to the existence of historical background and policies. After forty years of high-speed growth, even though the government has intentionally tilted various policies toward rural areas, the trend of the town feeding the county is still not present, and many social, economic and environmental dimensions between city and village give rise to staged development issues such as resource allocation and opportunities [23,24]. Moreover, even within the more developed urban agglomerations, the spatial pattern is also fragmented. Therefore, to promote coordinated development, China put forward the strategies of "integrated urban and rural development" and "new type of urbanization" in 2003 and 2012, respectively, and URCD has become one of the main objectives to further deepen the development after China's economic development has entered the new normal.

At present, many types of research have been conducted on URCD, which mainly includes theoretical combing [25], promotion measures [26,27] and coordination models [28]. Meanwhile, many scholars have also studied the connotation of URCD from various perspectives. For instance, Liu et al. (2016) argue that URCD refers to a good symbiotic relationship formed by balanced spatial distribution, smooth flow of economic factors, orderly society, and ecological harmony between city and village [29]. According to He et al. (2019), URCD refers to the distribution of regional production factor sources between the city and the countryside [30]. A high level of URCD can lead to an orderly distribution of factors within the region, while on the contrary, cities will further crowd out the development opportunities of the countryside. Wang et al. (2016) argue that URCD should include three dimensions, such as social, economic, and demographic, and establishes an evaluation system containing indicators of income expenditure, industry share, science and technology education, agricultural modernization, and quality of life for coordinated 
development evaluation [31]. Trapa et al. (2020) argue that URCD refers that urban and rural districts are closely connected through diverse linkages, which include population movements, resource mobility, etc, and it has significant implications for regional circulation and resource flows [32]. Hu et al. (2016) argue that the level of URCD is not the same as the level of economic development, but there is also the dilemma of the "Hu Huangyong line", and there is a risk that the gap will gradually widen [33]. With the Rio Declaration on Environment and Development issued by the United Nations Conference on Environment and Development (UNCED) in June 1992, sustainable development has gradually become the dominant development philosophy in various countries. The idea of balancing the efficiency and equity of development has been widely recognized and applied to many issues, such as labor policies [34], government compensatory payments [35] and income structure [36]. Similarly, as an important part of sustainable development, URCD possesses a similar concept and thus is applicable to be measured from both efficiency and equity dimensions. To summarize the existing studies, most scholars have used Geographic Information Systems (GIS) to study the relevant issues. Yet, due to the inherently static nature of GIS, this evaluation process only measures the spatio-temporal variation by collecting and updating periodical data [37]. However, the evolution process between efficiency and equity is dynamic and subject to a combination of multiple driving forces at different times, and thus the driving forces behind it need to be further explored from the top down based on the study of URCD.

In the process of exploring the driving forces in-depth, as an extension tool of GIS, the Cellular Automata model (CA) becomes the main method for some scholars to investigate the dynamic evolution of URCD [38]. However, CA focuses more on monitoring and simulating the spatiotemporal variation of URCD and lacks the combination and interpretation of its driving forces. On this basis, the System Dynamics model (SD) is introduced into the related field of research, which depicts the complex interactions between each component by viewing the urban-rural system as a collection of interconnected ones $[39,40]$, but SD also suffers from the lack of incorporating spatial factors into the model. For this purpose, spatial regression models have been proposed to analyze the driving forces of objects affected by spatial effects and have been gradually applied in the fields of land pattern evolution [41], climate change [42], but have been less frequently used to study issues related to urban-rural development.

Taken together, the existing studies still have certain shortcomings. First, the indicators selected by scholars in evaluating the level of URCD have been relatively well established [43,44], but it is still possible to further classify the indicators, for example, by measuring them from the perspective of integrated evaluation of efficiency and equity. Second, in terms of the selection of research objects, some scholars choose the whole of China as the study object [45], while others choose a certain province [46] or even a certain county [47] as the research object. Relatively little attention has been paid to urban cluster regions based on economic ties, sociocultural and geographic connections. Third, few scholars have examined the inclusion of spatial effects in the study of the driving forces of URCD, leading to a certain bias in the exploration. Therefore, this paper focuses on the efficiency and equity dimensions of URCD to construct a comprehensive assessment indicator system, evaluates the individual and comprehensive indexes of URCD using statistical data of 27 central cities in YRDUA, and investigates its spatial evolution patterns. On the premise of considering spatial effects, we explore the driving forces of URCD to enhance scientific understanding of its inner mechanism and ultimately provide a foundation for policy formulation.

\section{Methodology}

\subsection{Study Area}

The Yangtze River Delta urban agglomeration (YRDUA) covers a total of 41 cities in Shanghai, Zhejiang, Jiangsu, and Anhui. Considering factors such as data coherence and availability, and referring to the research areas mainly chosen by most scholars in studying 
various issues of YRDUA (e.g., [48-50]), this paper defines 27 cities such as Shanghai, Nanjing, Wuxi, Suzhou, Hangzhou, Ningbo and Hefei as the central area of YRDUA, and as the research object of this paper (as shown in Figure 1a,b). With a resident population of about $16 \%$ of the country's total population, a total economic volume of about $24 \%$ of the country, and an average urbanization rate of over $60 \%$, the region occupies a crucial strategic position in the modernization process of China. Since ancient times, this region has been one of the most economically developed and populous areas and was famous as the "land of fish and rice" due to its two convenient waterways, the Yangtze River and the Beijing-Hangzhou Grand Canal, as well as its favorable climate and fertile plains. In modern times, some cities in the region, including Shanghai and Ningbo, became early ports of commerce in China, thus gradually giving rise to commercial development and further promoting the economic expansion of cities in the region. In particular, in the 1980s and 1990s, private capital in the region became active, and township-enterprise-oriented town development models such as the "Southern Jiangsu Model" gradually emerged. With the gradual emergence of Pudong New Area and Suzhou Park, the internal cooperation of the region has become closer, and the overall industrial structure is dominated by high technology, manufacturing production and service industries, and promotes the common development of each city in the region. At present, as an early and highly developed urban agglomeration in China, the study of its development has a high degree of relevance.

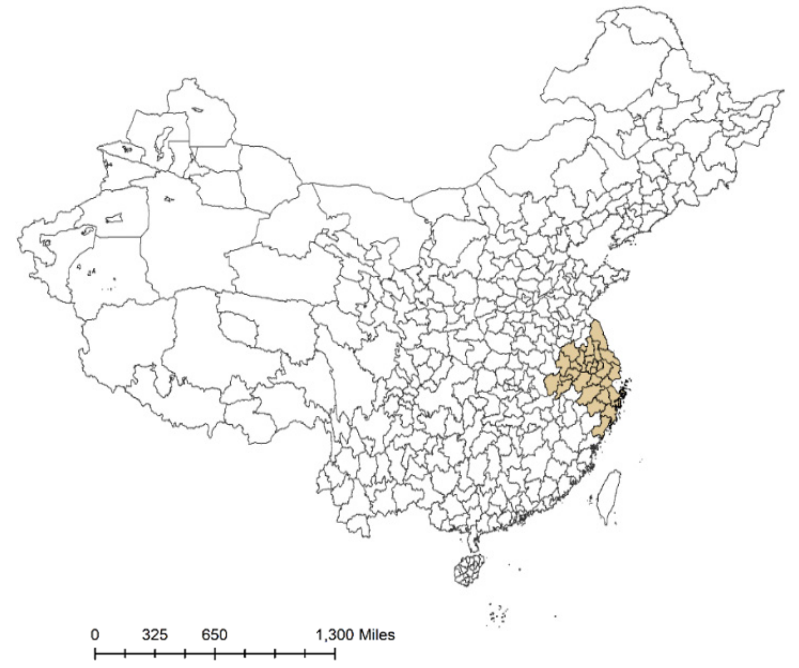

(a) China administrative divisions

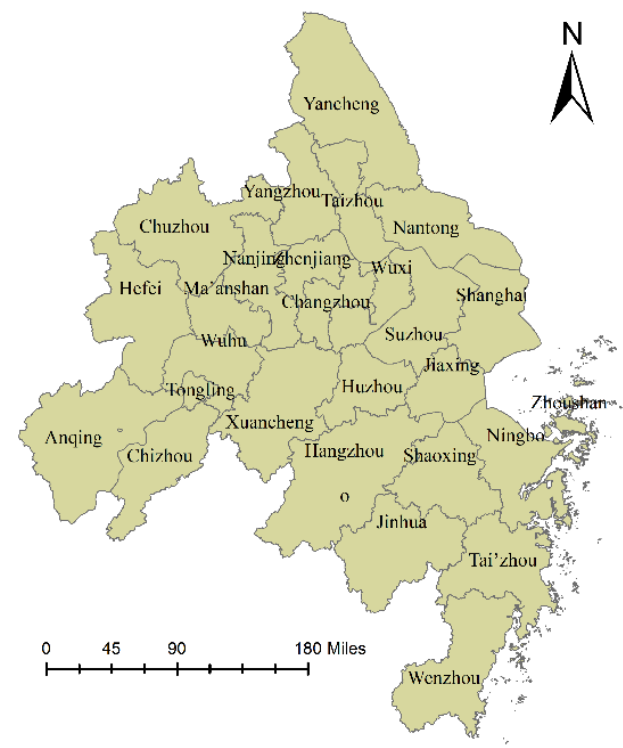

(b) the Yangtze River Delta urban agglomeration

Figure 1. Schematic diagram of the YRDUA.

\subsection{Indicator Assessment System of URCD}

At this point, the academic circle has not yet formed a consensus on the measurement system for assessing the level of URCD, and various insights on the construction of the system and the selection of indicators have been proposed by scholars. Zhang et al. (2018) construct a sustainable URCD evaluation index system based on three dimensions: "economy, society and environment" [51]. Zhang et al. (2015) measure the role of sustainable infrastructure projects in promoting URCD with the objectives of efficiency and equity [51]. Meanwhile, scholars such as Sun \& Liu (2015) [52] and Liu \& Li (2017) [53] have also made certain contributions in the construction of index systems. Thus, considering the requirements of accessibility, measurability and generalizability of indicators, this paper constructs the comprehensive indicator system according to the dimensions of efficiency and equity. The GDP per capita, the number of college students per 10,000 people, the number of hospital beds per 10,000 people, disposable income per capita, consumption 
expenditure per capita and greening coverage rate of built-up areas are categorized as efficiency indicators of URCD, and this target layer is defined as URED; and the bias of local financial support to agriculture, urban-rural dual structure index, urban-rural per capita disposable income ratio and urban-rural Engel coefficient ratio are categorized as equity indicators of URCD and this target layer is defined as URBD. Finally, the comprehensive assessment indicator system is formed, as shown in Table 1.

Table 1. The comprehensive assessment indicator system of URCD.

\begin{tabular}{|c|c|c|c|c|}
\hline General Layer & Target Layer & Guide Line Layer & Indicator Layer & Indicator Description \\
\hline \multirow{10}{*}{ URCD } & \multirow{6}{*}{ URED } & Economy & GDP per capita $(+)$ & $\begin{array}{l}\text { Total GDP (100 million yuan)/registered } \\
\text { residence population (person) }\end{array}$ \\
\hline & & Education & $\begin{array}{l}\text { The number of college } \\
\text { students per } 10,000 \\
\text { people }(+)\end{array}$ & $\begin{array}{l}\text { Total number of college students } \\
\text { (person)/number of registered population } \\
(10,000 \text { persons })\end{array}$ \\
\hline & & Medical treatment & $\begin{array}{l}\text { The number of hospital } \\
\text { beds per } 10,000 \text { people }(+)\end{array}$ & $\begin{array}{c}\text { Total number of beds in medical institutions } \\
\text { (person)/number of registered population } \\
(10,000 \text { persons })\end{array}$ \\
\hline & & Income & $\begin{array}{l}\text { Disposable income per } \\
\text { capita }(+)\end{array}$ & / \\
\hline & & Consumption & $\begin{array}{l}\text { Consumption expenditure } \\
\text { per capita }(+)\end{array}$ & / \\
\hline & & Environment & $\begin{array}{l}\text { Greening coverage rate of } \\
\text { built-up areas }(+)\end{array}$ & $\begin{array}{l}\text { Greening area of built-up area }\left(\mathrm{km}^{2}\right) / \text { total } \\
\text { area of built-up area }\left(\mathrm{km}^{2}\right)\end{array}$ \\
\hline & \multirow{4}{*}{ URBD } & Financial support & $\begin{array}{l}\text { The bias of local financial } \\
\text { support to agriculture }(+)\end{array}$ & $\begin{array}{c}\text { The proportion of local financial expenditure } \\
\text { on agriculture, forestry and water } \\
\text { conservancy/the proportion of regional } \\
\text { primary industry output value }\end{array}$ \\
\hline & & Industry structure & $\begin{array}{l}\text { Urban-rural dual structure } \\
\text { index }(+)\end{array}$ & $\begin{array}{l}\text { (Gross output value of primary industry/the } \\
\text { number of employees in primary } \\
\text { industry)/(gross output value of secondary } \\
\text { and tertiary industries/the number of } \\
\text { employees in secondary and } \\
\text { tertiary industries) }\end{array}$ \\
\hline & & Income gap & $\begin{array}{l}\text { Urban-rural per capita } \\
\text { disposable income ratio } \\
\qquad(-)\end{array}$ & $\begin{array}{l}\text { Per capita disposable income of urban } \\
\text { residents (yuan)/per capita disposable } \\
\text { income of rural residents (yuan) }\end{array}$ \\
\hline & & Consumption gap & $\begin{array}{l}\text { Urban-rural Engel } \\
\text { coefficient ratio }(-)\end{array}$ & $\begin{array}{l}\text { Engel coefficient of urban residents } \\
(\%) / \text { Engel coefficient of rural residents (\%) }\end{array}$ \\
\hline
\end{tabular}

\subsection{Driving Force System of URCD}

The driving forces behind URCD consist of both micro and macro levels together. At the micro-level, URCD refers to the process of continuous flow and reorganization between city and village, including population, land, resources, capital, information, technology and other factors. At the macro-level, it includes the role of government policies, social institutions and other systems in coordinating the city and the village in terms of functional positioning, factor allocation, labor division and collaboration, etc. The combined effect of the above two levels constitutes the driving force system of URCD, which ultimately affects the feelings of various social groups towards it.

To this extent, this paper first studies the micro-level influencing factors. Liu et al. (2013) have conducted a lot of research on this issue [54], and based on their research and combined with the previous section, this paper selects factors including (i) Population size (mainly portrays by number of the registered population). (ii) Industrialization degree (mainly portrays by gross industrial output per capita). (iii) Urbanization level (mainly portrays by urbanization rate). (iv) Fixed asset investment (mainly portrays by per capita fixed asset investment). (v) Government financial input (mainly portrays by per capita expenditure on science, education, culture, health and sports). (vi) Infrastructure construction (mainly portrays by highway density). (vii) Foreign Investment (mainly portrays by 
per capita actually utilized foreign investment). (viii) Consumption (mainly portrays by per capita retail sales of social consumer goods). A total of eight factors and their indicators above are studied as relevant factors influencing URCD. On this foundation, this paper then focuses on the factors at the macro-level in terms of government policies and social institutions, and finally thus finds the fundamental driving forces. The factors, indicators and descriptions of the URCD system are shown in Table 2.

Table 2. The driving forces system of URCD.

\begin{tabular}{|c|c|c|c|}
\hline Serial Number & Factors & Indicators & Indicator Description \\
\hline $\mathrm{X} 1$ & Population size & Number of registered population & / \\
\hline $\mathrm{X} 2$ & Industrialization degree & Gross industrial output per capita & $\begin{array}{l}\text { Industrial added value }(10,000 \text { yuan }) / \text { number of } \\
\text { registered population }(10,000 \text { persons })\end{array}$ \\
\hline $\mathrm{X} 3$ & Urbanization level & Urbanization rate & $\begin{array}{l}\text { Urban population }(10,000 \text { persons }) / \text { number of } \\
\text { registered population ( } 10,000 \text { persons }) \\
\text { Total investment in fixed assets }\end{array}$ \\
\hline $\mathrm{X} 4$ & Fixed asset investment & Per capita fixed asset investment & $\begin{array}{c}(10,000 \text { yuan }) / \text { number of registered population } \\
(10,000 \text { persons })\end{array}$ \\
\hline X5 & Government financial input & $\begin{array}{l}\text { Per capita expenditure on science, } \\
\text { education, culture, health and sports }\end{array}$ & $\begin{array}{c}\text { Expenditure on science, education, culture } \\
(10,000 \text { yuan }) / \text { number of registered population } \\
(10,000 \text { persons })\end{array}$ \\
\hline X6 & Infrastructure construction & Highway density & Highway mileage $(\mathrm{km}) /$ land area $\left(\mathrm{km}^{2}\right)$ \\
\hline $\mathrm{X} 7$ & Foreign investment & $\begin{array}{l}\text { Per capita actually utilized } \\
\text { foreign investment }\end{array}$ & $\begin{array}{c}\text { Actually utilized foreign investment } \\
\text { (10,000 dollars)/number of registered } \\
\text { population (10,000 persons) }\end{array}$ \\
\hline X8 & Consumption & $\begin{array}{l}\text { Per capita retail sales of social } \\
\text { consumer goods }\end{array}$ & $\begin{array}{c}\text { Retail sales of social consumer goods } \\
\text { (yuan)/number of registered population } \\
(10,000 \text { persons })\end{array}$ \\
\hline
\end{tabular}

\subsection{Data Source}

The statistical data of 27 cities in the YRDUA in 2000, 2005, 2010 and 2015 are selected as the samples for this study. The reasons for choosing these four years include the following. First, the years chosen for study coincide with the end of China's recurring five-year national development plan, which allows us to compare and test the impact of the implementation of each phase of the plan on urban and rural development. Second, the selection of equally spaced periods facilitates the subsequent objective spatiotemporal analysis modeling. Finally, the Yangtze River Delta Regional Plan (2010-2015) was promulgated by China in 2010, so this year became a key point to study the implementation of regional synergistic development in the YRDUA. Consequently, the selected years can be used as a typical object to study the URCD in YRDUA. Also, to ensure that the data are comparable with each other, the raw economic data for calculation during the study period are based on comparable prices in 2000.

All the original data used in this study are obtained from the China Statistical Yearbook, the Compilation of Statistics for 60 Years of New China, China Urban Statistical Yearbook, China Rural Statistical Yearbook and the statistical yearbooks of 27 cities in the YRDUA from 2000 to 2016, the statistical reports published by the National Bureau of Statistics of China for all years, and the Chinese economic and social statistical database. Some of the missing values are filled in using linear interpolation.. In general, this part of missing data has little impact on the final evaluation index values and the determination of subsequent influencing factors.

\subsection{Evaluation Method}

\subsubsection{Principal Component Analysis (PCA)}

Principal component analysis (PCA) is an analytical and statistical method that converts multiple elements with correlation into several unrelated composite indicators. Under the principle of ensuring the least loss of information, PCA reduces the dimensionality of the original indicators, omits some irrelevant indicators, and converts the original indicators into less comprehensive indicators that can reflect the research phenomenon, which can simplify the complex research and improve the research efficiency while ensuring 
the research accuracy [55]. Generally speaking, the process of PCA is performed in the following 6 steps. (i) Calculate the correlation coefficient matrix $\mathrm{R}$ of the evaluation indexes. (ii) Calculate the eigenvalues of the correlation coefficient matrix $\mathrm{R}$ and the corresponding eigenvectors. (iii) Calculate the variance contribution and cumulative variance contribution of the principal components. (iv) Determine the number of principal components. (v) Calculate the loadings of the principal components. (vi) Calculate the score of each principal component.

\subsubsection{Exploratory Spatial Data Analysis Model (ESDA)}

Exploratory Spatial Data Analysis (ESDA) is a statistical analysis method that helps analyze the spatial effects of a phenomenon by analyzing spatial autocorrelation, which can be utilized in analyzing spatial dependence and heterogeneity [56]. This method brings together various spatial data analysis techniques to explore the spatial distribution characteristics of the data and reveal the spatial mechanism of action between research objects through visualization. According to the first law of Geography, all things are interconnected, and the closer the spatial distance, the stronger the connection between them and vice versa [57]. Spatial autocorrelation is a measurement for the strength of the connection between neighboring things. This method measures the covariance between neighboring observation units by comparing the similarity of observations and the similarity between their observation space locations [58]. Generally, the Spatial Autocorrelation is mainly classified into two types on research: Global Spatial Autocorrelation (e.g., Moran's I index, Geary's C index, etc.) and Local Spatial Autocorrelation (e.g., Getis-Ord's Gi, Moran scatter plot, etc.).

\subsubsection{Spatial Regression Model}

In traditional statistics, if the data to be regressed do not exhibit spatial effects between them, the model parameters can be estimated directly using general estimation methods (e.g., ordinary least squares models) [59]. Normally, a benchmark model is needed for comparative reference when performing spatial econometric model analysis. The ordinary least squares model (OLS) is the most common benchmark model, as shown in Equation (1).

$$
y=X \beta+\varepsilon
$$

where: $y$ is the dependent variable, $X$ is the independent variable, $\beta$ is the parameter and $\varepsilon$ is the error term.

However, since spatial data or data containing geographic information have certain spatial effects, models that consider spatial regression effects are needed to describe and explain the related problems arising from spatial effects. This includes the Spatial Lag Model (SLM) and the Spatial Error Model (SEM).

The SLM takes into account the spatial correlation of the dependent variable, which can be expressed by Equation (2).

$$
y=\rho W_{y}+X \beta+\varepsilon
$$

where: $y$ is the dependent variable, $\rho$ is the regression coefficient, $W$ is the weight, $X$ is the independent variable, $\beta$ is the parameter and $\varepsilon$ is the error term.

The SEM, on the other hand, considers the error process through the covariance of the differences, which can be expressed in Equation (3).

$$
\begin{gathered}
y=X \beta+\mu \\
\mu=\lambda W_{\mu}+\varepsilon
\end{gathered}
$$

where: $y$ is the dependent variable, $W$ is the weight, $X$ is the independent variable, $\beta$ is the parameter, $\mu$ is the intercept distance, $\lambda$ is the spatial autoregressive coefficient and $\varepsilon$ is the error term. 
To analyze this spatial effect, this paper investigates the relevant issues through the choice of three models: OLS, SLM and SEM. Anselin gives a flow chart of the empirical analysis for spatial econometric modeling (Figure 2).

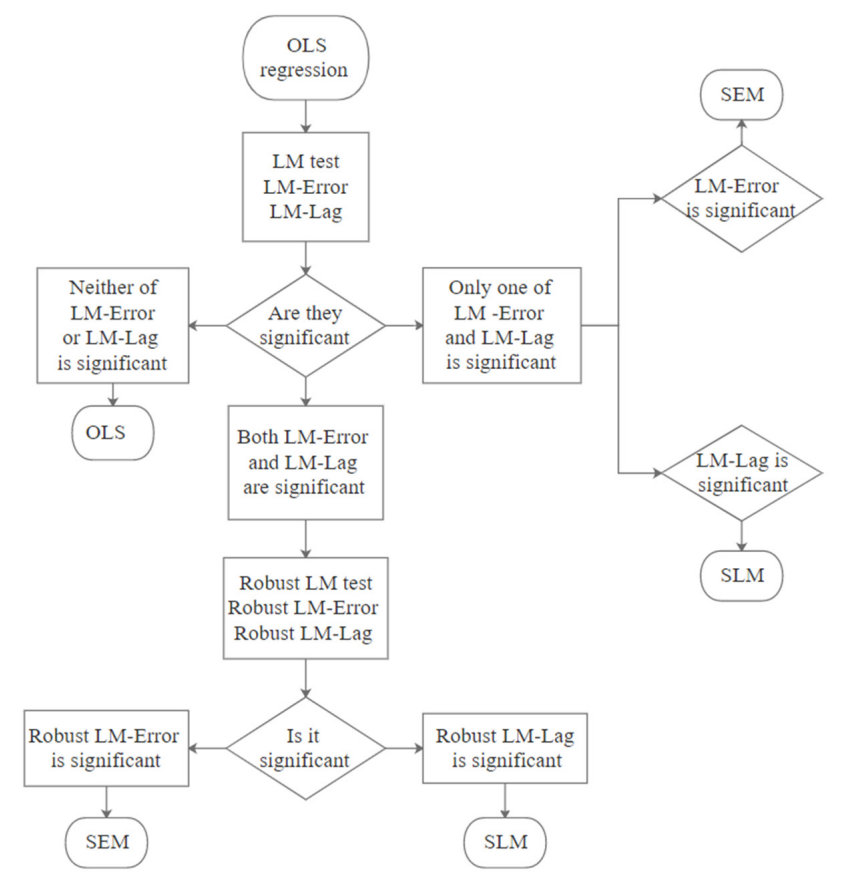

Figure 2. The general process of spatial econometric modeling.

\section{Spatiotemporal Analysis}

\subsection{Calculation of the Values of URCD in the YRDUA}

For effectively assessing the real level of URCD, we calculate the value on the foundation of the specific data of 27 cities in the YRDUA using the PCA method with the help of SPSS software. First, the raw data are preprocessed, i.e., the data are normalized and standardized (among them, the normalization is done by taking the inverse and the standardization is done by the Z-score standardization method). Second, the specific expressions of $\mathrm{m}$ principal components $(\mathrm{Fi})$ and the calculation model of comprehensive principal component assessment value are extracted. Finally, the comprehensive level of URCD of 27 cities in YRDUA for each year is estimated by the derived model.

In general, various criteria can be utilized for principal component extraction. For example, Kaiser (1960) suggests that the number of principal components can be determined based on the criterion that the corresponding eigenvalues of principal components are greater than one [60], while Ca Ttell (1968) suggests that the extraction of principal components can be performed by the empirical criterion of cumulative variance contribution of $70 \%$ or more and the steep slope test criterion [61]. In this paper, the variance decomposition and principal component extraction are carried out according to the principle of eigenvalue greater than 1 in combination with the above criteria, and three principal components are extracted in 2000, 2005, 2010 and 2015, and their cumulative variance contributions are $80.351 \%, 71.340 \%, 73.640 \%$ and $70.665 \%$, respectively, all of which passed the tests of the above criteria. This result indicates that the extracted Fi already contains most of the information in the 10 original indicator variables, which shows it is effective to use PCA for assessing the comprehensive level of URCD of the 27 cities in YRDUA. In summary, the standardized values of indicators are substituted into the above model, and finally the values of the comprehensive level of URCD and their rankings in 2000, 2005, 2010 and 2015 are calculated as shown in Table 3. 
Table 3. The value and rank of URCD of 27 cities in 2000, 2005, 2010 and 2015.

\begin{tabular}{|c|c|c|c|c|c|c|c|c|}
\hline City & $\begin{array}{l}\text { URCD } \\
(2000)\end{array}$ & $\begin{array}{l}\text { Rank } \\
(2000)\end{array}$ & $\begin{array}{l}\text { URCD } \\
(\mathbf{2 0 0 5 )}\end{array}$ & $\begin{array}{l}\text { Rank } \\
(2005)\end{array}$ & $\begin{array}{l}\text { URCD } \\
(2010)\end{array}$ & $\begin{array}{l}\text { Rank } \\
(2010)\end{array}$ & $\begin{array}{l}\text { URCD } \\
(\mathbf{2 0 1 5 )}\end{array}$ & $\begin{array}{l}\text { Rank } \\
\text { (2015) }\end{array}$ \\
\hline Shanghai & 17.423 & 1 & 13.530 & 1 & 8.194 & 5 & 9.368 & 3 \\
\hline Hangzhou & 13.262 & 3 & 12.432 & 3 & 12.291 & 2 & 10.030 & 1 \\
\hline Ningbo & 4.189 & 6 & 6.589 & 6 & 5.027 & 8 & 5.986 & 6 \\
\hline Wenzhou & 2.047 & 11 & 4.416 & 7 & -2.057 & 19 & 2.252 & 10 \\
\hline Jiaxing & 3.807 & 7 & 2.819 & 11 & 3.631 & 9 & 4.169 & 7 \\
\hline Huzhou & -0.211 & 15 & 2.857 & 10 & 1.414 & 13 & -0.550 & 15 \\
\hline Shaoxing & 2.728 & 10 & 3.253 & 8 & 1.630 & 12 & 2.920 & 9 \\
\hline Jinhua & -1.290 & 16 & -0.736 & 15 & -1.738 & 17 & 0.773 & 13 \\
\hline Tai'zhou & -3.283 & 20 & -0.829 & 16 & -1.670 & 16 & -2.293 & 19 \\
\hline Zhoushan & -1.293 & 12 & -1.417 & 17 & 5.072 & 6 & 2.000 & 11 \\
\hline Nanjing & 13.754 & 2 & 10.718 & 4 & 10.631 & 3 & 8.080 & 4 \\
\hline Suzhou & 9.335 & 4 & 12.704 & 2 & 12.976 & 1 & 9.514 & 2 \\
\hline Wuxi & 4.468 & 5 & 10.462 & 5 & 9.867 & 4 & 6.567 & 5 \\
\hline Changzhou & 3.009 & 9 & 3.209 & 9 & 5.029 & 7 & 3.808 & 8 \\
\hline Yangzhou & -0.031 & 14 & -5.585 & 19 & -1.549 & 15 & -4.276 & 22 \\
\hline Zhenjiang & 0.494 & 13 & 0.857 & 13 & 2.112 & 10 & -0.090 & 14 \\
\hline Nantong & -2.667 & 19 & -5.176 & 18 & -1.957 & 18 & -3.096 & 20 \\
\hline Taizhou & -2.461 & 18 & -6.351 & 21 & -5.316 & 20 & -5.999 & 21 \\
\hline Yancheng & -7.443 & 23 & -10.478 & 23 & -7.360 & 23 & -8.874 & 24 \\
\hline Hefei & 3.716 & 8 & 2.728 & 12 & 2.110 & 11 & -0.945 & 16 \\
\hline Wuhu & -6.082 & 21 & -5.819 & 20 & -5.816 & 21 & -1.197 & 17 \\
\hline Ma'anshan & -1.697 & 17 & -0.368 & 14 & 0.600 & 14 & -1.340 & 18 \\
\hline Tongling & -7.168 & 22 & -6.953 & 22 & -5.820 & 22 & 1.416 & 12 \\
\hline Anqing & -15.892 & 27 & -14.583 & 27 & -14.240 & 27 & -10.998 & 27 \\
\hline Chuzhou & -12.999 & 25 & -11.071 & 25 & -12.036 & 26 & -9.528 & 25 \\
\hline Chizhou & -15.735 & 26 & -12.567 & 26 & -10.357 & 24 & -6.984 & 23 \\
\hline Xuancheng & -11.800 & 24 & -10.640 & 24 & -10.828 & 25 & -10.020 & 26 \\
\hline
\end{tabular}

The following conclusions can be extracted from Table 3. First, from the overall distribution of regional scores, the four regions of southern Jiangsu, northern Zhejiang, northern Anhui and Shanghai are always relatively high-level, while the scores of northern Jiangsu, southern Zhejiang and parts of Anhui are generally low-level. Second, in terms of provinces, the four-year average scores of URCD in Zhejiang Province are 2.838, 3.265, 2.400 and 2.810, respectively; the four-year average scores of URCD in Jiangsu Province are 2.495, 1.706, 2.826 and 0.848 respectively; and the four-year average scores of URCD in Anhui Province are $-8.457,-7.284,-6.698$ and -4.950 , respectively. In other words, the overall URCD level of Jiangsu and Zhejiang provinces is slightly better than that of Anhui province. Finally, in terms of city-specific scores, the highest-ranked cities in each study year are Shanghai in 2000 and 2005, Suzhou in 2010 and Hangzhou in 2015, with scores of 17.423, 13.530, 12.976 and 10.030; the lowest-ranked city in each study year is Anqing, with scores of $-15.892,-14.583,-14.240$ and -10.998 . In terms of the gap in scores, the overall gap between cities with the highest and lowest scores is relatively large in 2000, while the differences in 2005, 2010 and 2015 all fall back to different degrees, indicating that while the gap in URCD between regions within YRDUA gradually decreases, the overall development tends to be stable, with a greater degree of improvement for cities at the low-level development as a whole.

\subsection{The Spatial Pattern of URCD}

\subsubsection{Spatial Autocorrelation Analysis of URCD}

The spatial distribution heterogeneity and characteristics of the temporal evolution of the integrated level of URCD in YRDUA can be revealed by the Global Moran's I index and Moran scatter plot. In this paper, we apply ESDA with the help of GIS and Geoda software to calculate the Moran's I index of URCD of 27 cities in the YRDUA in 2000, 2005, 2010 and 2015, and draw Moran scatter plots for the corresponding periods. In particular, the results of the calculations are presented as scatter plots in the four quadrants of the Cartesian coordinate system (the horizontal axis indicates the integrated level of URCD and the vertical axis indicates its spatial lag) according to the spatial clustering and dispersion 
characteristics between each city and its neighboring cities, and thus classify each city into four spatial types. The cities in the first and third quadrants are HH (high-high) and LL (low-low) respectively, indicating homogeneity (high or low level) of URCD values of the city itself and its neighboring cities, while the cities in the second and fourth quadrants are LH (low-high) and HL (high-low), respectively, indicating heterogeneity (high level on one side and low level on the other side) of URCD values of the city itself and its neighboring cities.

After calculation, Figure 3. shows the Moran's I index and Moran's I scatterplot of the level of URCD of the YRDUA in 2000, 2005, 2010 and 2015. It can be seen that the value of the comprehensive level of URCD and its spatial lagging value are roughly positively correlated. The Moran's I index for each year is 0.393, 0.496, 0.425 and 0.306, which are positive and significantly greater than zero, suggesting a strong positive spatial correlation among provinces. At the same time, randomized simulations are conducted to test the spatial autocorrelation of the above data; 99,999 randomized simulations are conducted using Geoda software, and the statistical distribution plots are all very close to normal distribution, and the results of each test indicate that the observations have strong positive spatial autocorrelation, which means that the comprehensive level of similar URCD (including both high-level values and low-level values) of provinces tend to show spatial clustering. This spatial autocorrelation is manifested as below.
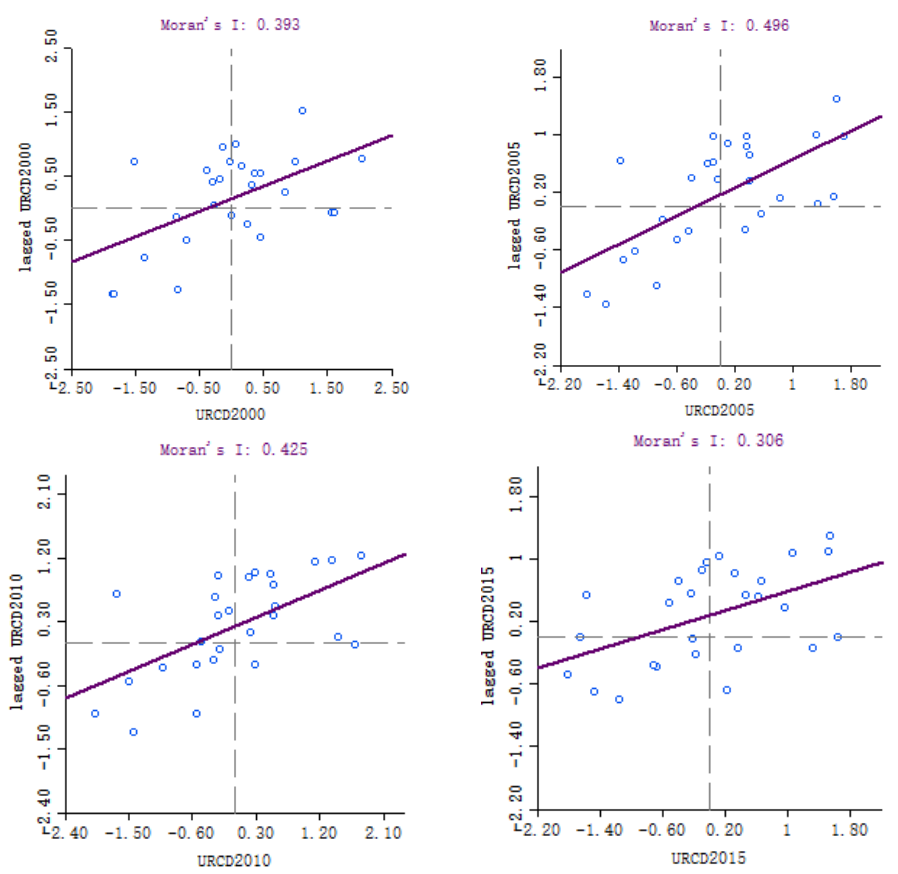

Figure 3. Moran's I value and Moran's scatter plot of URCD in YRDUA.

(i) Analyzing the trend, the Moran's I index of the URCD of YRDUA shows an increasing trend between 2000 and 2005, from 0.393 in 2000 to 0.496 in 2005, which indicates that during this period cities with close URCD values in the YRD tend to be more geographically concentrated. However, by 2010 and 2015, the Moran's I index of URCD in YRDUA declines to 0.425 and 0.306 , indicating that following the stronger growth in the previous period, the positive spatial correlation of URCD in the cities slowly falls back during this period, and the spatial differences in the development of individual cities intensify to some extent.

(ii) Analyzing the magnitude of change, the change in Moran's I index from 2000 to 2005 is 0.103 , while that from 2005 to 2010 is -0.071 and from 2010 to 2015 is -0.119 . This suggests that the positive spatial correlation of URCD among the cities in YRDUA increased between 2000 and 2005, and the spatial relationship tends to decline from 2005 to 2010 and 2010 to 2015 , with repeated fluctuations. 
(iii) Analyzing the spatial autocorrelation type changes, HH-type cities and LL-type cities account for a larger proportion of the cities studied in the four study periods, and there is a great degree of spatial proximity peer effect of URCD in the YRDUA. In other words, when the URCD of neighboring cities around the region is high-level (low-level) URCD, the region is more likely to become a city with high-level (low-level) URCD, thus forming a local spatial agglomeration pattern of "the weak is always weak, the strong is always strong". The main reason for the formation of this spatial pattern is that the neighboring cities in the YRDUA are more similar in economic, social, cultural and resource endowments. With closer in spatial distance, lower transportation costs, easier and faster access to information, and frequent inter-city connections, there is a great degree of correlation in the implementation of policies and measures concerning urban-rural integration and development, thus forming a geographical spatial spillover effect. Meanwhile, the results demonstrate that the URCD of YRDUA shows a certain trend of polarization, with a certain degree of agglomeration in both high-level and low-level areas.

\subsubsection{Spatial Pattern Evolution of URCD, URED and URBD}

Based on the Arcgis spatial analysis model, we classify the URCD of 27 cities in YRDUA in 2000, 2005, 2010 and 2015 into five levels: highest, higher, medium, lower and lowest, and the corresponding spatial distribution diagrams are drawn in Figure 4 . The five levels are arranged according to the color sequence of "Red-Orange-Yellow-Green -Blue", and the color sequence matches the five levels from high to low. Besides, since the URCD includes two dimensions of urban-rural efficient development (URED) and urban-rural balanced development (URBD), the evolution of these two integrated levels is analyzed simultaneously using the above-mentioned method (Figures 5 and 6).
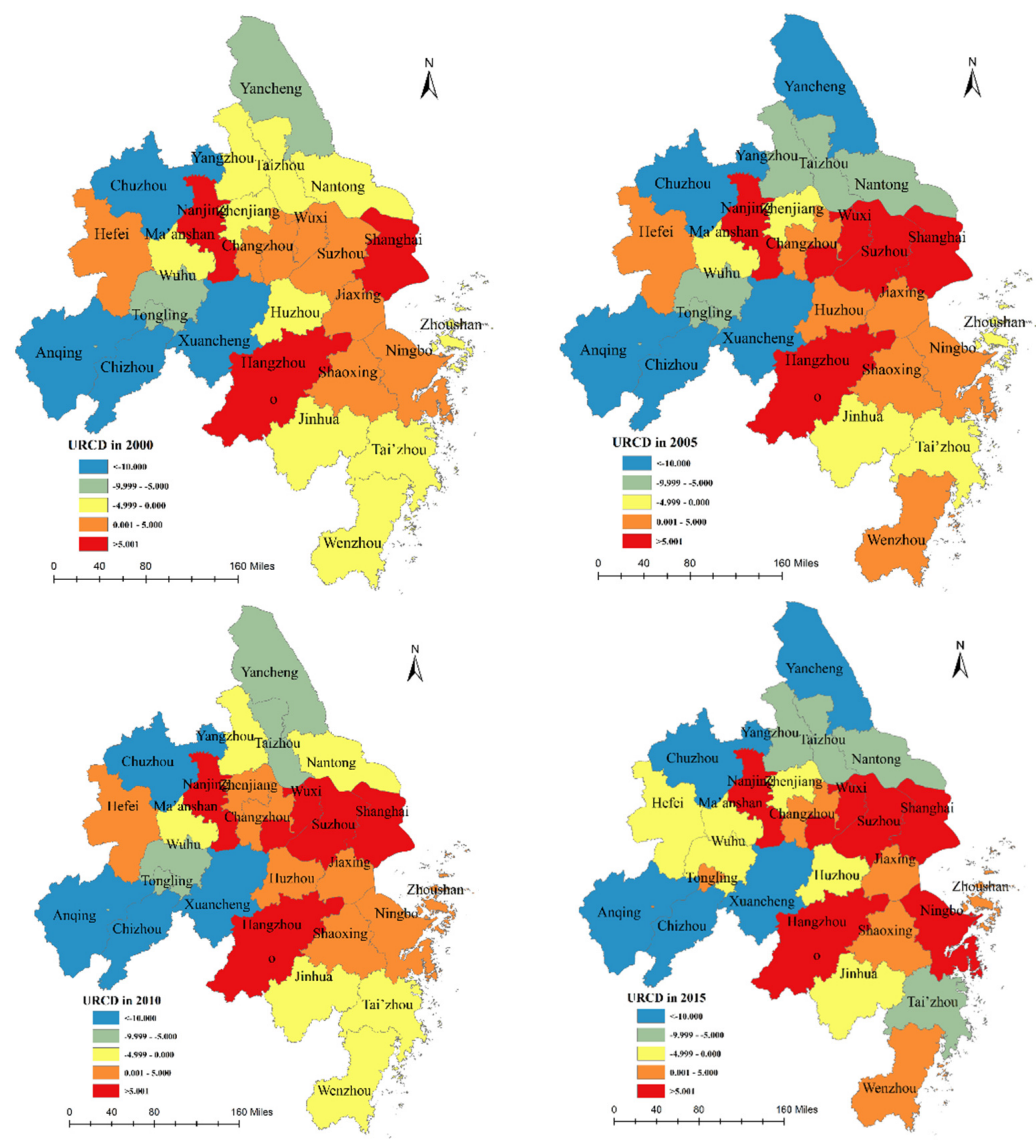

Figure 4. The spatial distribution of URCD (2000-2015). 

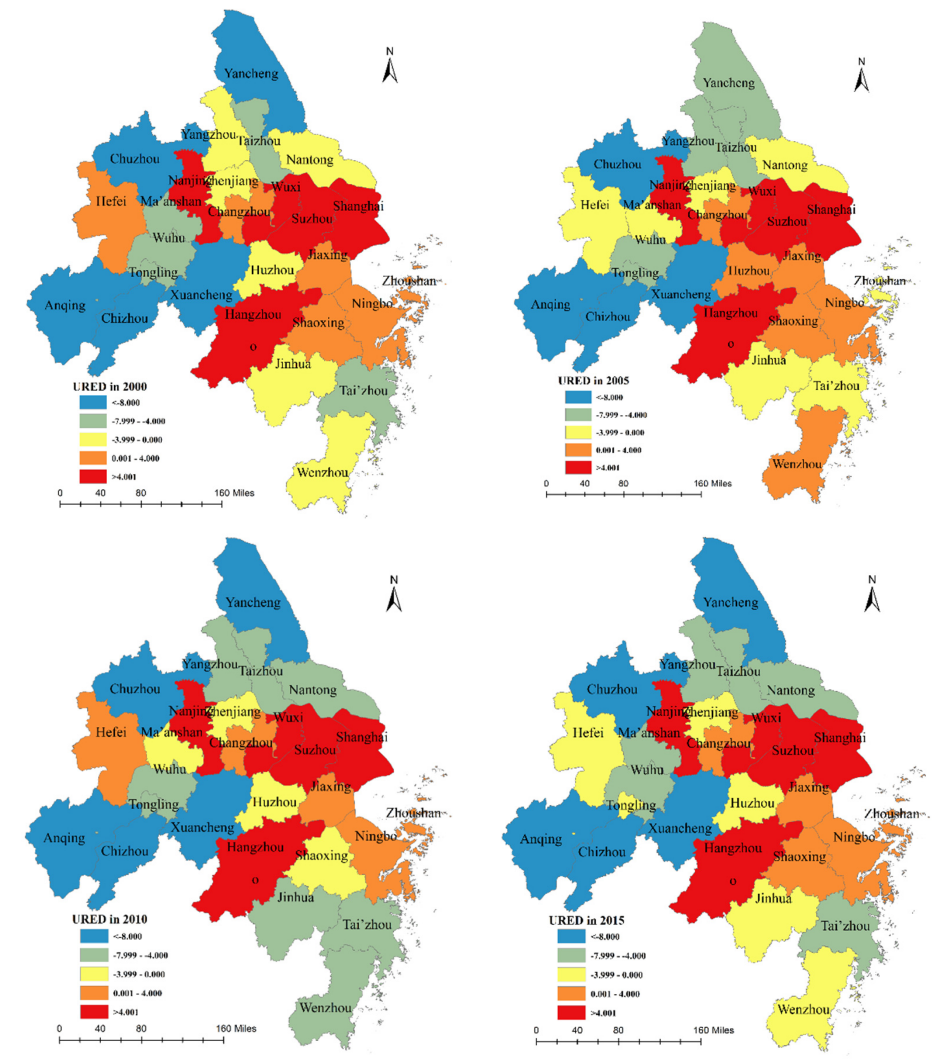

Figure 5. The spatial distribution of URED (2000-2015).
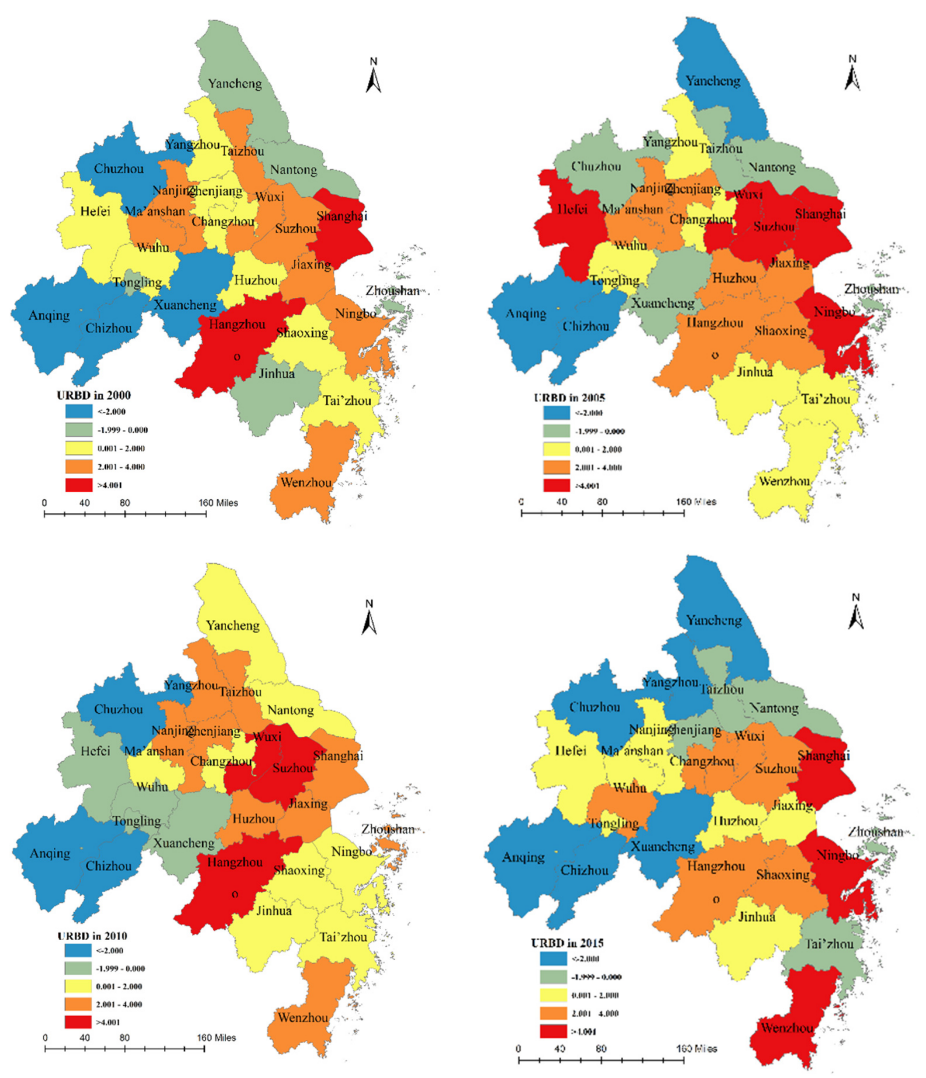

Figure 6. The spatial distribution of URBD (2000-2015). 
By comparing the spatial patterns of the three indicators of YRDUA in each study year, two direct conclusions can be drawn. First, the spatial patterns of URCD and URED are relatively stable, while the spatial patterns of URBD produce greater volatility. Second, the spatial patterns of URCD and URED are relatively similar in the same study year, while there are some differences with the spatial patterns of URBD. The following is a specific analysis of the distribution characteristics and spatial pattern evolution of URCD, URED and URBD in each study year.

(i) 2000 to 2005. In terms of the rank and number of cities in URCD, the changes are mainly concentrated in northern Jiangsu and southern Zhejiang, and the number of both high-level and low-level cities has increased. First, Suzhou, Wuxi, Changzhou and Nanjing in Jiangsu Province, Hangzhou, Ningbo, Shaoxing, Jiaxing in Zhejiang Province and Shanghai form an obvious highest- and higher-level agglomeration area. This pattern remains unchanged during 2000-2005, and Wenzhou City in Zhejiang Province is ranked from the medium level to the higher level. Second, the number of medium level cities decreases from 10 to 5 due to the high-level change, and the change is mainly concentrated in Yangzhou, Taizhou and Nantong in Jiangsu Province. Third, the number of lower level and lowest level cities is relatively consistent, mainly concentrated in some areas of Anhui Province and the northern part of Jiangsu Province, with Yancheng City in Jiangsu Province decreasing from lower level to lowest level. The overall distribution and changes in the number of URBD in each city produce some variability in terms of their rank and number of cities. For example, among the highest and higher URCD clusters mentioned above, Changzhou's URBD is only at a medium level in 2000 and 2005, while Wuxi, Suzhou and Ningbo's URBD increased from a higher level to the highest level between 2000 and 2005. In addition, Hefei's URBD increases from medium to high level.

(ii) 2005 to 2010. First, the number of cities above medium level increases from 12 to 13, which shows that the overall situation of URCD in YRDUA has improved. Second, in terms of distribution, the higher- and highest-level cities are still concentrated and show a strong aggregation. The changes are mainly concentrated in Jiangsu Province, and the development of southern Zhejiang Province has also changed. The overall situation in Jiangsu Province has improved, with Yangzhou and Nantong cities rising from lower to medium level. Wenzhou in Zhejiang Province declines from a higher level to a medium level. Throughout the period from 2000 to 2010, the developmental change of URCD shows a repeated trend of decreasing and then rebounding, indicating that the developmental change of URCD is somewhat repetitive. Similarly, the overall distribution and change of each city in terms of URED is more consistent with URCD, but it can be noted that there is an overall decline in URED in Zhejiang Province, with Jinhua, Tai'zhou and Wenzhou dropping from medium and higher levels to lower level respectively. However, there are major differences in URBD. First, the total number of highest- and higher-level cities remains the same in terms of quantity, but the number of highest level cities decreases from 5 to 3 . The overall development of Jiangsu Province has improved, with Yancheng, Taizhou, Yangzhou and Nantong all increasing. Second, in terms of distribution, the regions where the higher and highest level cities located are further narrowed and concentrated, mainly in the central-eastern region of the YRD, while the low-level regions are primarily concentrated in some parts of Anhui Province, and the aggregation is further strengthened.

(iii) 2010 to 2015. In terms of the number and levels in URCD of the cities, the distribution of the high-level development pattern of YRD has been consolidated. First, the number of the highest- and higher-level cities remains unchanged at 13, while the number of medium level cities has slightly changed from 6 to 5 . Second, in terms of distribution, cities including Nanjing, Wuxi and Suzhou in Jiangsu Province, Jiaxing, Hangzhou, Shaoxing, Ningbo in Zhejiang Province and Shanghai have formed a region of the higher or highest level of URCD, while Yancheng and Taizhou in Jiangsu 
Province, and Anqing, Chuzhou, Xuancheng and Chizhou in Anhui Province have formed a region of low-level, and the URCD of the remaining cities has changed slightly during the five years. Similarly, the overall distribution and change of each city in terms of URED is more consistent with URCD. However, in terms of URBD, the overall situation has decreased. First, in terms of number, the cities at the highest level remain largely unchanged, while the number of cities at the medium level decreases from 8 to 6. Many cities with high-level URBD, such as Yangzhou, Taizhou, Nanjing and Nantong experience different degrees of decline in URBD; and the number of cities at the medium level also decreases from 7 to 6 . Second, in terms of distribution, the overall URBD in Anhui Province has increased during the study period, with Hefei and Tongling rising from lower to medium level, but the overall URBD level in Anhui Province still needs to be improved.

From a comprehensive view of the four study periods, the URCD of each city in the YRDUA can be roughly categorized into three categories. The first category is high in both URED and URBD, for example, Suzhou, Shanghai, Hangzhou, Wuxi, Nanjing and Jiaxing, whose URED and URBD are both at higher and highest levels in the four study periods, so the development experience of these cities is therefore worthy of further consideration by other cities. In the second category, most cities have low-level URED and URCD, and they are mainly concentrated in the northern part of Jiangsu and the western region of Anhui. These cities tend to have a weak development foundation and need to learn more experience from neighboring regions at a later stage, and to balance efficiency and equity in the development process and strengthen all-round development. The third category is cities with URED and URBD which have a certain degree of high-level and low-level repetition in the development process. These cities are characterized by their high URED and URBD in the early stage of development, but in the last decade, a mismatch between URED and URCD begin to arise. The main reason for this phenomenon is that most of them are more economically developed and tend to focus too much on enhancing efficiency but neglect equity in the development process, resulting in structural imbalance in urban and rural development. For example, Wenzhou experienced an increase in URCD in the early stage of development in 2005, but its URBD decreased in 2010 and increased again in 2015. Comparing URED and URBD, it can be found that the changes of the two also experienced similar fluctuations and in opposite directions, i.e., equity is lower when efficiency is high. This phenomenon is largely since Wenzhou focused on development efficiency in the early stage of development and experienced a "wild growth" process. Especially around 2000, relying on the opportunity of China's accession to the World Trade Organization (WTO), Wenzhou's private economy pushed a large number of light industrial products to the whole country and even the whole world, and various levels of urban development were improved. However, this private economy-dominated model led to a lack of government supervision, insufficient public investment, a serious mismatch between urban construction and the degree of economic development, and a bottleneck in the efficiency and fairness of development. In recent years, Wenzhou has started to improve urban infrastructure construction and other aspects in addition to development, so the equity of urban and rural development has gradually risen. Depending on the basic situation of most cities, we can conclude that, in general, URBD and URED need to achieve simultaneous development, and on this basis, URCD can be further promoted.

\section{Driving Forces}

\subsection{The Spatial Regression Model for the Driving Forces}

The URCD of YRDUA has a clear spatial and temporal divergence. The emergence of this phenomenon is influenced by the combination of deep-seated driving forces, which are composed of micro-level factors and macro-level institutions and policies. To further quantify the driving forces, this chapter will first analyze the micro-level factors and then analyze the macro-level institutions and policies concerning the changes in the factors. From the above discussion, it can be found that the Moran's I values of each city in YRDUA 
are positive and significantly greater than zero, which indicates the existence of spatial autocorrelation and aggregation in space, and a spatial regression analysis model can be constructed. The covariance analysis is conducted for each influence index. It is tested that there is no covariance between two of the indicators to be regressed. There is a noticeable spatial correlation in URCD, which implies the data are spatially distributed non-independently, so the spatial effect model is estimated using the maximum likelihood method based on the traditional least-squares method. Although Moran's I test shows significant spatial autocorrelation of the residuals, this test does not determine which specific spatial regression model should be selected. Therefore, the judgment needs to be made by the general process of spatial econometric modeling combined with the Lagrange multiplier test, the results of which are shown in Table 4.

Table 4. Estimated results of influencing factors of URCD using the chosen models.

\begin{tabular}{|c|c|c|c|c|c|c|c|c|}
\hline Year & \multicolumn{2}{|l|}{2000} & \multicolumn{2}{|c|}{2005} & \multicolumn{2}{|c|}{2010} & \multicolumn{2}{|l|}{2015} \\
\hline \multirow[t]{2}{*}{ Model } & \multicolumn{2}{|l|}{ SLM } & \multicolumn{2}{|c|}{ OLS } & \multicolumn{2}{|c|}{ SEM } & \multicolumn{2}{|l|}{ SLM } \\
\hline & Coefficient (z) & $p$ & Coefficient (z) & $p$ & Coefficient (z) & $p$ & Coefficient (z) & $p$ \\
\hline Constant (C) & $0.007(0.202)$ & 0.840 & 0.000 & 1.000 & $\begin{array}{c}-0.024 \\
(-0.332)\end{array}$ & 0.739 & $0.013(0.212)$ & 0.832 \\
\hline $\mathrm{X} 1$ & $-0.015(0.255)$ & 0.736 & $0.161(1.651)$ & 0.116 & $\begin{array}{l}-0.314 \\
(-5.906)\end{array}$ & 0.000 & $-0.577(-4.196)$ & 0.000 \\
\hline $\mathrm{X} 2$ & $0.454(3.789)$ & 0.000 & $0.121(1.182)$ & 0.253 & $0.003(0.060)$ & 0.952 & $-0.145(-2.176)$ & 0.030 \\
\hline $\mathrm{X} 3$ & $0.602(6.029)$ & 0.000 & $0.432(2.994)$ & 0.008 & $0.449(4.957)$ & 0.000 & $1.138(7.497)$ & 0.000 \\
\hline $\mathrm{X} 4$ & $\begin{array}{l}-0.558 \\
(-2.448)\end{array}$ & 0.014 & $0.351(2.173)$ & 0.043 & $0.254(3.993)$ & 0.000 & $-0.420(-3.061)$ & 0.002 \\
\hline$X 5$ & $0.180(3.805)$ & 0.000 & $\begin{array}{c}-0.077 \\
(-0.596)\end{array}$ & 0.559 & $0.314(4.328)$ & 0.000 & -0.135 (1.016) & 0.310 \\
\hline X6 & $0.119(1.826)$ & 0.068 & $\begin{array}{l}-0.118 \\
(-1.241)\end{array}$ & 0.231 & $0.187(3.120)$ & 0.002 & $-0.122(-1.582)$ & 0.113 \\
\hline $\mathrm{X} 7$ & $0.140(2.364)$ & 0.018 & $0.116(0.905)$ & 0.377 & $\begin{array}{c}-0.155 \\
(-3.037)\end{array}$ & 0.002 & $0.506(3.653)$ & 0.000 \\
\hline $\mathrm{X} 8$ & $0.349(2.432)$ & 0.015 & $0.153(1.019)$ & 0.322 & $0.062(0.951)$ & 0.342 & $0.088(0.881)$ & 0.378 \\
\hline Spatial lag term & $0.162(2.167)$ & 0.030 & / & / & / & / & $0.222(1.776)$ & 0.076 \\
\hline Spatial error term & / & / & / & / & $0.469(2.265)$ & 0.023 & / & / \\
\hline \multicolumn{9}{|c|}{ Statistical Tests } \\
\hline $\mathrm{R}^{2}$ & 0.966 & & 0.90 & & 0.95 & & 0.901 & \\
\hline$\delta^{2}$ & 0.032 & & 0.14 & & 0.04 & & 0.094 & \\
\hline $\log L$ & 7.941 & & -6.6 & & 3.87 & & -6.612 & \\
\hline AIC & 4.117 & & 31.37 & & 10.24 & & 33.224 & \\
\hline SC & 17.075 & & 43.03 & & 21.90 & & 46.182 & \\
\hline
\end{tabular}

For the data of 2000, the LM-Lag test is significant at the 0.1 level (LM-Lag $=4.673$, $p=0.052)$, the LM-Error test is not significant, and the SLM model is selected directly. For 2005, the LM-Lag test and LM-Error test are not significant at the 0.1 level, and the OLS regression model is selected. For 2010, the LM-Lag test is not significant at the 0.1 level and the LM-Error test is significant at the 0.1 level (LM-Lag = 3.606, $p=0.057$ ), and the SEM model is selected directly. For 2015, the LM-Lag test is significant at the 0.1 level $(\mathrm{LM}-\mathrm{Lag}=2.731, p=0.098)$ and the LM-Error test is not significant, and the SLM model is chosen directly. The specific regression results and model fit results tests are shown in Table 4.

As can be seen in Table 4 , the $\mathrm{R}^{2}$ of each regression model for each year exceeds 0.9 , the $\delta^{2}$ are smaller, and the log likelihood value, AIC value and SC value test results are better than other choices under the same conditions, indicating that the model has a better fit. After comparison, it is found that the spatial lag term or spatial error term of the model selected for all years except 2005 passed the significance test, indicating that URCD in neighboring regions and the status of socioeconomic and other factors would have a significant impact on the region. 


\subsection{Results of Spatial Regression Analysis of Driving Forces}

The model results (Table 4) show that the main influencing indicators of URCD in YRDUA in 2000 are gross industrial output per capita $X 2$, urbanization rate $X 3$, per capita fixed asset investment $X 4$, per capita expenditure on science, education, culture, health and sports X5, highway density X6, per capita actually utilized foreign investment $\mathrm{X} 7$ and per capita retail sales of social consumer goods $X 8$. Among them, $X 4$ is significant at the 0.1 level and has a negative impact coefficient, which plays a negative driving role, while the remaining indicators play a positive driving role.

In 2005, the main influencing indicators of URCD in YRDUA are urbanization rate X3 and per capita fixed asset investment $X 4$, which are significant at the 0.1 level and have positive impact coefficients, playing a positive driving role.

In 2010, the main influencing indicators of URCD in YRDUA are number of registered population $X 1$, urbanization rate $X 3$, per capita fixed asset investment $X 4$, per capita expenditure on science, education, culture, health and sports $X 5$, highway density $X 6$, and per capita actually utilized foreign investment $X 7$, among which $X 1$ and $X 7$ are significant at the 0.1 level with negative coefficients and play a negative role. The rest of the indicators play a positive role.

In 2015, the main influencing indicators of URCD in YRDUA are number of registered population $\mathrm{X} 1$, gross industrial output per capita $\mathrm{X} 2$, urbanization rate $\mathrm{X} 3$, per capita fixed asset investment $X 4$, and per capita actually utilized foreign investment $X 7$. Among them, $X 1, X 2$, and $X 4$ are significant at the 0.1 level with negative coefficients, which play a negative driving role, while the rest of the indicators play a positive driving role.

From the above results, it can be seen that the URCD of YRDUA in 2000 is mainly influenced by the factors of industrialization degree, urbanization level, fixed asset investment, government financial input, infrastructure construction, foreign investment and consumption. It indicates that around 2000, the overall level of URCD is relatively low, and the development of several aspects such as urbanization development, infrastructure level improvement, industrialization development, government financial investment, foreign investment and consumption demand expansion are all conducive to the improvement of the overall level of URCD. The fixed asset investment factor plays a negative role, indicating that the amount of per capita fixed asset investment around 2000 is insufficient, and development has a strong constraining effect.

The spatial correlation of URCD in YRDUA decreases in 2005, and the results of estimation using the OLS model show that only two factors, urbanization level and fixed asset investment, are significant. This indicates that the increase in urbanization level and the increase in fixed assets investment effectively contributed to the further development of urban-rural integration compared to the year 2000. The insignificant indicator of population size indicates that the total population size has little influence on URCD compared with the population structure (i.e., urbanization rate). The insignificant factor of infrastructure construction may be related to the constraints of topography on accessibility. And the insignificant factor of foreign investment indicates that the level of economic development is still relatively low at the beginning of the 21st century, and foreign investment does not play an essential role in promoting economic development and even urban-rural development.

The URCD of YRDUA in 2010 is mainly influenced by factors such as population size, urbanization level, fixed asset investment, government financial input, infrastructure construction and foreign investment. The factor of population size plays a negative role, indicating that the population problems such as continuous rural population outflow, separation of people and land, and population aging make population growth an obstacle to urban-rural integration. The industrialization level is no longer a significant factor, indicating that the traditional industrialization process is no longer the main factor hindering the development of urban-rural integration by around 2010. The factor of urbanization level is significant, indicating that the improvement of population structure at this stage further promotes URCD. The increase of fixed asset investment and government financial investment further promotes URCD in the economic and social environments and other 
aspects. The highway density indicator is significant at 0.1 level with positive correlation coefficient, indicating that the road network of cities in the YRDUA has been developed significantly around 2010, which accelerates the transportation between the city and the village including resources, population and finished products, and effectively promotes the connection between areas. The foreign investment factor plays a negative influence, indicating that the actual amount of foreign investment utilized per capita is insufficient and becomes a hindering factor for urban-rural development.

The URCD of YRDUA in 2015 is mainly influenced by factors such as population size, industrialization degree, urbanization level, fixed asset investment and foreign investment. The indicator of gross industrial output per capita becomes significant at the 0.1 level but with a negative impact coefficient, indicating that the traditional industrialization process may begin to lead to the cities plundering the resources of the rural areas and becoming one of the factors that eat away at the rural development process. The population problem still exists after 2010 and the significant factor of urbanization level indicates that the continuous improvement of the demographic structure is still a favorable factor to promote the coordinated development. The per capita expenditure on science, education, culture, health and sports is no longer significant at the 0.1 level, indicating that government financial input to the current level is no longer the main factor driving URCD. Per capita fixed asset investment is significant at the 0.1 level with a negative impact coefficient, indicating that insufficient investment in fixed assets in YRDUA at this stage makes economic development less dynamic, thus affecting the coordinated development. Per capita retail sales of social consumer goods indicator is no longer significant at the 0.1 level, suggesting that simply increasing consumption demand can no longer promote URCD by 2015. The overall consumption level of YRDUA has already reached a high level, and the marginal effect brought by consumption is no longer very significant, so further attention needs to be paid to issues such as consumption structure. The per capita actually utilized foreign investment indicator is significant at the 0.1 level with a positive coefficient of influence, suggesting that foreign investment has begun to play a role in promoting urban-rural development, and may benefit rural areas through, among other things, the acquisition of rural land for the construction of plants and the recruitment of large numbers of workers, bringing about a catalytic effect on URCD.

Comprehensively considering the changes in the factors that influenced URED in the urban agglomeration in the past 15 years, combined with the evolutionary patterns of URCD, URED and URBD in each city of YRDUA can be found as follows.

(i) In the early stage of development, URCD is highly correlated with URED, while URED mainly relies on economic development, so many factors related to economic development such as urbanization level, industrialization, infrastructure construction, and government financial investment can effectively promote URCD. In fact, in the early stage of development, land finance is the main means of development relied on by local governments, especially under the demand of industrialization and urbanization. Local governments expropriated a large amount of rural land and sold it to obtain fiscal revenue while transforming the rural population into the urban population and transforming rural collective land into urban construction land. These revenues were then used to build infrastructure such as roads, railways, bridges, etc., or to provide a range of public services. In particular, for urban agglomerations, under the joint action of the two operating mechanisms of agglomeration and diffusion, various factors including capital, technology, talent, information, etc. flow continuously between cities, and factors such as regional and transportation accessibility of cities have a great impact on the flow of the above factors, which easily lead to the formation and optimization of inter-city spatial economic linkage network structure. Taking the transportation field as an example, the Shanghai-Nanjing intercity railroad and Shanghai-Hangzhou intercity railroad, which were opened around 2010, have built a "two-hour commuting circle" around Shanghai and gradually expanded its radiation range. With this advantage, the cities along its route, including Shanghai, 
Nanjing, Suzhou, Jiaxing, Hangzhou and Ningbo, have closer communication, so the northern Zhejiang, southern Jiangsu and Shanghai areas where the above cities are located have further become high-level URCD region.

(ii) In the later stage of development, especially during 2010-2015, it is obvious from the regression model that consumption, investment, industrialization process and government financial input are no longer the main factors influencing URCD, and even once played an inverse role, and the demographic factors also hindered it to a certain extent. The root cause of this phenomenon is that under the traditional dual economy system, local governments often simply and roughly transform the appearance of rural areas into that of cities, but fail to fundamentally explore the development advantages of rural areas and realize the transformation of rural lifestyles. A large number of people and resources are flowing into cities, which makes them gain more development benefits than rural areas, thus further widening the urban-rural gap. Influenced by the idea of "development is the first priority", this phenomenon is especially obvious in cities with high URED, such as Nanjing and Wuxi, which do not reach high-level URBD. However, as China's economic development enters a new normal period, promoting URED is no longer the only goal, and URBD has also become an important part of URCD. Therefore, for cities within YRDUA, such as cities in northern Zhejiang, southern Jiangsu, northern Anhui and Shanghai regions, considering that their industrialization urbanization process and infrastructure construction have been perfected, and government financial investment and foreign investment in residents' consumption level are also at a high level, the marginal benefit brought by simply increasing the input of these factors is not enough. Therefore, the focus of these cities should be on how to distribute factors equitably between city and village. This requires the government to design at the institutional level so that the rural areas can discover economic growth points and direct development factors to the rural areas naturally rather than artificially. For instance, Suzhou has promoted agricultural parks in rural areas, in addition to building special industries such as "e-commerce industrial parks", and providing financial and institutional support, which has achieved good results. On the other hand, cities in other regions of YRDUA still have some room for improvement in URED, and can still promote development through industrial transfer, financial investment, and improvement of infrastructure construction, etc. However, in the process of development, we should also focus on URBD to avoid large urban-rural differences.

\section{Conclusions and Discussion}

Situated on the background of the development and evolution of urban-rural relations in YRDUA, this paper proposes the concept of URCD based on many existing studies and further discusses the concept in URED and URBD, respectively. Through an in-depth discussion of the evolutionary patterns of URCD from perspectives of efficiency and equity in URED and URBD, respectively, in the 27 central cities in YRDUA between 2000 to 2015 and their main driving forces, some insights into their development history during the study period are gained. Based on the above understanding we can further promote the development within YRDUA in various dimensions, such as economic, social and infrastructure, and promote the development of each city within the region to improve the development efficiency and at the same time enhance the development equity.

This paper constructs a complete evaluation system to assess the URCD of 27 cities in YRDUA, which is divided into sub-dimensions of URED (including economy, education, medical treatment, income, consumption and environment) and URBD (including financial support, industrial structure, income gap, consumption), covering all important factors reflecting a city's URCD. Based on the above, this paper provides an in-depth analysis of the URCD of each city in YRDUA.

(i) Exploratory spatial data analysis. This paper uses ESDA to characterize the spatial evolution of the integrated level of URCD of each city in YRDUA in each year, and 
concludes that there is a positive spatial correlation between the integrated level of URCD in the region, and the high-level regions and the low-level regions show a certain degree of aggregation individually.

(ii) Spatial distribution pattern analysis. This paper analyzes the changes of URCD, URED and URBD in the YRDUA from 2000 to 2015. From the perspective of regional differences, URCD of YRDUA, in general, shows the spatial distribution characteristics of decreasing from the central part to the north and south parts in order, i.e., the highlevel cities are in northern Zhejiang, southern Jiangsu, northern Anhui and Shanghai regions, and the low-level cities are in the southern part, northern Jiangsu and some parts of Anhui Province. Compared with the spatial distribution of URCD, that of URED also shows a similar pattern in general, and the distribution pattern of each year during the study period is also very similar. In contrast, the spatial distribution of URBD is different, and some cities with high URED are not at the high level of URBD, which shows that many cities have the problem of "focusing on efficiency at the expense of equity".

To reveal the driving forces of URCD in YRDUA, this paper first uncovers the main factors influencing the comprehensive level of URCD over the years based on the power indicators. Considering the role of spatial interactions between cities, the spatial regression model is chosen for further study, and it is concluded that the factors vary in different periods. In the early stage, many factors including fixed asset investment, infrastructure construction and urbanization level play a vital role in promoting URCD. However, with the continuous advancement of development, some factors such as consumption level and government financial investment used to play an important role, but their influence gradually weakens in the new stage. Some factors such as industrialization degree, foreign investment, fixed asset investment, etc. have positive driving effects in some years but negative driving effects in other years. The level of urbanization has effectively promoted the process of URCD throughout the study period. Secondly, based on the changes in factors, this paper concludes that the traditional approach of simply transforming rural areas into cities in shape and appearance is only the most superficial form and is no longer feasible. In the new era of development, what we need to do is to re-examine the interaction between elements, structures, functions and systems between town and country, that is, how to more effectively allocate the organic flow and concentration of development factors and establish a synergistic mechanism including population, land and industry, to promote the organic integration of urban development and rural construction.

It can be concluded that, as one of the more important urban agglomerations in China, YRDUA is already at a high level in many aspects including infrastructure, public services and financial investment, but there is still great variability in URCD among cities within it, and there is also much room for improvement. For cities in different development levels, the main influencing factors for promoting URCD are different, so it is necessary for each city to consider the situation of URED and URBD together and make a distinction in the top-level government design. At present, how to study URCD from the perspective of internal factor flow is still a complex task, so there are certain shortcomings in this paper. From the research method, the problem involves topology and system dynamics, which is why it is possible to reveal the intrinsic relationship between each influencing factor and URCD through quantitative models. From the research scale, it is necessary to further analyze the evolution of the integrated level of URCD with the county as a unit. Therefore, more in-depth research is needed in the future, using specific cities as typical cases.

Author Contributions: D.T. conceived and designed the study; W.H. and J.S. completed the paper in English and revised it critically for important intellectual content; M.M. gave many good research advices and revised the manuscript. All authors have read and agreed to the published version of the manuscript.

Funding: This paper was supported by the National Social Science Foundation of China (20BGL300).

Institutional Review Board Statement: Not applicable. 
Informed Consent Statement: Not applicable.

Conflicts of Interest: The authors declare no conflict of interest.

\section{References}

1. Lewis, W.A. The dual economy revisited. Manch. Sch. 1979, 47, 211-229. [CrossRef]

2. Todaro, M.P. A model of labor migration and urban unemployment in less developed countries. Am. Econ. Rev. 1969, 59, 138-148.

3. Karst, K.L.; Friedmann, J. Regional Development Policy: A Case Study Of Venezuela; MIT Press: Cambridge, MA, USA, 1969 ; Volume 49.

4. Parr, J.B. Growth-pole strategies in regional economic planning: A retrospective view. part origins and advocacy. Urban Stud. 1999, 36, 1195-1215. [CrossRef]

5. Lysgård, H.K. The assemblage of culture-led policies in small towns and rural communities. Geoforum 2019, 101, 10-17. [CrossRef]

6. Oedl-Wieser, T.; Hausegger-Nestelberger, K.; Dax, T.; Bauchinger, L. Formal and informal governance arrangements to boost sustainable and inclusive rural-urban synergies: An analysis of the metropolitan area of styria. Sustainability 2020, $12,10637$. [CrossRef]

7. Amezcua, A.; Ratinho, T.; Plummer, L.A.; Jayamohan, P. Organizational sponsorship and the economics of place: How regional urbanization and localization shape incubator outcomes. J. Bus. Ventur. 2020, 35, 105967. [CrossRef]

8. Yang, X. Analysis on China's urban-rural integration: The perspective of path-dependence. Open J. Soc. Sci. 2016, 4, 133-140. [CrossRef]

9. Xie, Y.; Jiang, Q. Land arrangements for rural-urban migrant workers in China: Findings from Jiangsu Province. Land Use Policy 2016, 50, 262-267. [CrossRef]

10. Li, Y.; Hu, Z. Approaching integrated urban-rural development in China: The changing institutional roles. Sustainability 2015, 7, 7031-7048. [CrossRef]

11. Batyuk, B.; Kudla, N. Non-agricultural activities as a measure of revitalisation of rural areas. Sci. Messenger Lnu Vet. Med. Biotechnol. 2019, 21, 120-124. [CrossRef]

12. Ariyo, O.; Fadupi, G.; Adepoju, O. Rural urban differentials in lifestyle and food security of older persons. Afr. J. Food Agric. Nutr. Dev. 2020, 40-49.

13. Song, J. Gender and employment in rural China. Gend. Employ. Rural China 2017, 1-149. [CrossRef]

14. Wong, C.Y.; Elbegsaikhan, M. Geographical indications in development contexts: Function, supply chain and pursuit of rural industrial development. J. World Intellect. Prop. 2020, 23, 712-735. [CrossRef]

15. Thomas, K.R.; Meyfroidt, P. Organizing anarchy: The food security-biodiversity-climate crisis and the genesis of rural land use planning in the developing world. Land Use Policy 2014, 36, 239-247. [CrossRef]

16. Galadima, M. Rural infrastructure strategy for poverty reduction in nigeria: Yobe ifad-cbardp experience. Eur. Sci. J. 2014, 1, 605-612.

17. Zhu, K.; Zhang, L.; Yuan, S.; Zhang, X.; Zhang, Z. Health financing and integration of urban and rural residents' basic medical insurance systems in China. Int. J. Equity Health 2017, 16, 194. [CrossRef] [PubMed]

18. He, C.; Peng, L.; Liu, S.; Xu, D.; Xue, P. Factors influencing the efficiency of rural public goods investments in mountainous areas of China-based on micro panel data from three periods. J. Rural Stud. 2016, 47, 612-621. [CrossRef]

19. Molero-Simarro, R. Inequality in China revisited. The effect of functional distribution of income on urban top incomes, the urban-rural gap and the gini index, 1978. China Econ. Rev. 2017, 42, 101-117. [CrossRef]

20. Potrafke, N.; Roesel, F. The urban-rural gap in healthcare infrastructure: Does government ideology matter? Reg. Stud. 2020, 54, 340-351. [CrossRef]

21. Wang, D.; Wang, J.; Li, H.; Li, L. School context and instructional capacity: A comparative study of professional learning communities in rural and urban schools in China. Int. J. Educ. Dev. 2017, 52, 1-9. [CrossRef]

22. Nguyen, Q.; Kim, D.C. Reconsidering rural land use and livelihood transition under the pressure of urbanization in vietnam: A case study of hanoi. Land Use Policy 2020, 99. [CrossRef]

23. Liu, Y.; Huang, J.; Zikhali, P. The bittersweet fruits of industrialization in rural china: The cost of environment and the benefit from off-farm employment. China Econ. Rev. 2016, 38, 1-10. [CrossRef]

24. Ma, C.; Jiang, Y.; Qi, K. Investigating the urban-rural integrated town development strategy on the basis of the study of rural forms in Nantong, China. Front. Archit. Res. 2020, 10, 190-201. [CrossRef]

25. Zhang, M.; Wu, W.; Zhong, W.; Zeng, G.; Wang, S. The reshaping of social relations: Resettled rural residents in Zhenjiang, China. Cities 2017, 60, 495-503. [CrossRef]

26. Zhu, H.; Deng, F.; Liang, X. Overall urban-rural coordination measures-a case study in Sichuan Province, China. Sustainability 2017, 9, 189. [CrossRef]

27. Chen, S. Difference of urban and rural development in Binzhou from the perspective of urban and rural coordinating. J. Landsc. Res. 2018, 10, 35-42.

28. Ma, L.; Cheng, W.; Qi, J. Coordinated evaluation and development model of oasis urbanization from the perspective of new urbanization: A case study in Shandan County of Heixi Corridor, China. Sustain. Cities Soc. 2018, 39, 78-92. [CrossRef]

29. Liu, J.; Liu, Y.; Yan, M. Spatial and temporal change in urban-rural land use transformation at village scale-A case study of Xuanhua District, North China. J. Rural Stud. 2016, 47, 425-434. [CrossRef]

30. He, Q.; Tan, S.; Yin, C.; Zhou, M. Collaborative optimization of rural residential land consolidation and urban construction land expansion: A case study of huangpi in Wuhan, China. Comput. Environ. Urban Syst. 2019, 74, 218-228. [CrossRef] 
31. Wang, Y.; Liu, Y.; Li, Y.; Li, T. The spatio-temporal patterns of urban-rural development transformation in China since 1990. Habitat Int. 2016, 53, 178-187. [CrossRef]

32. Thapa, K.; Sukhwani, V.; Deshkar, S.; Shaw, R.; Mitra, B.K. Strengthening urban-rural resource flow through regional circular and ecological sphere (r-ces) approach in Nagpur, India. Sustainability 2020, 12, 8663. [CrossRef]

33. Hu, Z.; Wang, Y.; Liu, Y.; Long, H.; Peng, J. Spatio-temporal patterns of urban-rural development and transformation in east of the "Hu Huanyong Line", China. Isprs Int. J. Geo-Inf. 2016, 5, 24. [CrossRef]

34. Haferkamp, A.; Fetchenhauer, D.; Belschak, F.; Enste, D. Efficiency versus fairness: The evaluation of labor market policies by economists and laypeople. J. Econ. Psychol. 2009, 30, 527-539. [CrossRef]

35. Cherkaska, V. Mechanisms of state regulation of protection of internal markets of the agrarian sector. Public Adm. Reg. Dev. 2019, 3, 178-191.

36. Dai, Y.; Kong, D.; Xu, J. Does fairness breed efficiency? Pay gap and firm productivity in China. Int. Rev. Econ. Financ. 2017, 48, 406-422. [CrossRef]

37. Shawul, A.A.; Chakma, S. Spatiotemporal detection of land use/land cover change in the large basin using integrated approaches of remote sensing and gis in the upper Awash Basin, Ethiopia. Environ. Earth Sci. 2019, 78, 141. [CrossRef]

38. Zhang, X.; Zhou, J.; Song, W. Simulating urban sprawl in china based on the artificial neural network-cellular automata-markov model. Sustainability 2020, 12, 4341. [CrossRef]

39. Morgan, J.S.; Graber-Naidich, A. Small system dynamics model for alleviating the general practitioners rural care gap in Ontario, Canada. Socioecon. Plann. Sci. 2019, 66, 10-23. [CrossRef]

40. Pejic Bach, M.; Tustanovski, E.; Ip, A.W.H.; Yung, K.L.; Roblek, V. System dynamics models for the simulation of sustainable urban development: A review and analysis and the stakeholder perspective. Kybernetes 2019, 49, 460-504. [CrossRef]

41. Shi, Y.; Lv, X.; Guo, G. Spatiotemporal pattern and driving mechanism of cultivated land use transformation based on gis and spatial metrology. China Land Sci. 2019, 33, 51-60. (In Chinese)

42. Zhao, X.; Deng, C.; Huang, X.; Kwan, M.P. Driving forces and the spatial patterns of industrial sulfur dioxide discharge in China. Sci. Total Environ. 2017, 577, 279-288. [CrossRef] [PubMed]

43. Wang, Y.; Liu, Y.; Yan, B.; Al, E. Spatial patterns and influencing factors of urban-rural coordinated development in China. Sci. Geogr. Sin. 2016. [CrossRef]

44. Zhang, W.; Derudder, B.; Wang, J.; Shen, W. Regionalization in the Yangtze River Delta, China, from the perspective of inter-city daily mobility. Reg. Stud. 2018, 52, 528-541. [CrossRef]

45. Chen, S.; Akita, N. Rural complex an attempt to coordinate the development of urban and rural areas in China. Int. Rev. Spat. Plan. Sustain. Dev. 2021, 9, 93-106. [CrossRef]

46. Ma, L.; Chen, M.; Fang, F.; Che, X. Research on the spatiotemporal variation of rural-urban transformation and its driving mechanisms in underdeveloped regions: Gansu Province in western China as an example. Sustain. Cities Soc. 2019, 50, 1-13. [CrossRef]

47. Cui, J.; Luo, J.; Kong, X.; Sun, J.; Gu, J. Characterising the hierarchical structure of urban-rural system at county level using a method based on interconnection analysis. J. Rural Stud. 2019. [CrossRef]

48. Xu, X.; Wang, Y. Study on spatial spillover effects of logistics industry development for economic growth in the Yangtze River Delta city cluster based on spatial durbin model. Int. J. Environ. Res. Public Health 2017, 14, 1508. [CrossRef]

49. Zhang, X. Estimation of eco-efficiency and identification of its influencing factors in China's Yangtze River Delta urban agglomerations. Growth Chang. 2020, 51, 792-808. [CrossRef]

50. Liu, J.; Dou, Y.; Lu, Y.; Yang, L. Study on the spatial distribution characteristics of urban innovation power in Yangtze River Delta urban agglomeration. Iop Conf. Ser. Earth Environ. Sci. 2020, 474. [CrossRef]

51. Zhang, X.; Wu, Y.; Skitmore, M.; Jiang, S. Sustainable infrastructure projects in balancing urban-rural development: Towards the goal of efficiency and equity. J. Clean. Prod. 2015, 107, 445-454. [CrossRef]

52. Sun, K.; Liu, J. Construction of urban-rural integration evaluation system in nanchang city and empirical studies. J. Landsc. Res. 2015, 33, 552-558.

53. Liu, Y.; Li, Y. Revitalize the world's countryside. Nature 2017, 548, 275-277. [CrossRef] [PubMed]

54. Liu, Y.; Lu, S.; Chen, Y. Spatio-temporal change of urban-rural equalized development patterns in China and its driving factors. J. Rural Stud. 2013, 32, 320-330. [CrossRef]

55. Dillon, W.R.; Goldstein, M. Multivariate Analysis: Methods and Applications; Wiley: New York, NY, USA, 1984.

56. Anselin, L. Local Indicators of Spatial Association—Lisa. Geogr. Anal. 1995, 27, 93-115. [CrossRef]

57. Tobler, W. A computer movie simulating urban growth in the detroit region. Econ. Geogr. 1970, 46, 234-240. [CrossRef]

58. Xiao, G.; Hu, Y.; Li, N.; Yang, D. Spatial autocorrelation analysis of monitoring data of heavy metals in rice in China. Food Control 2018, 89, 32-37. [CrossRef]

59. Cano, J.; O'neill, W.D.; Penn, R.D.; Blair, N.P.; Kashani, A.H.; Ameri, H.; Kaloostian, C.L.; Shahidi, M. Classification of advanced and early stages of diabetic retinopathy from non-diabetic subjects by an ordinary least squares modeling method applied to octa images. Biomed. Opt. Express 2020, 11, 4666. [CrossRef]

60. Kasier, H.F. The application of electronic computers to factor analysis. Educ. Psychol. Meas. 1960, 20, 141-151. [CrossRef]

61. Ca Ttell, R.B. Handbook of multivariate experimental psychology. Perspect. Individ. Differ. 1968, 5, 256. 